\title{
Distribution of foraging shearwaters relative to inner front of SE Bering Sea
}

\author{
J. Jahncke ${ }^{1, *}$, K. O. Coyle ${ }^{2}$, S. I. Zeeman ${ }^{3}$, N. B. Kachel ${ }^{4}$, G. L. Hunt Jr. ${ }^{1}$ \\ ${ }^{1}$ Department of Ecology and Evolutionary Biology, University of California at Irvine, Irvine, California 92697, USA \\ ${ }^{2}$ Institute of Marine Science, University of Alaska, Fairbanks, Alaska 99775, USA \\ ${ }^{3}$ Department of Biological Sciences, University of New England, Biddeford, Maine 04005, USA \\ ${ }^{4}$ NOAA/Pacific Marine Environmental Laboratory, 7600 Sandpoint Way NE, Seattle, Washington 98115, USA
}

\begin{abstract}
We examined the hypothesis that short-tailed shearwaters Puffinus tenuirostris aggregate to forage at the inner front of the SE Bering Sea because of enhanced production there. We tested this hypothesis by comparing primary production, the distribution of euphausiids and the distribution of shearwaters relative to the front during late spring and late summer/early fall of 1997 , 1998 and 1999. We found enhanced primary production at the front and offshore of the front during summer but not during spring. Primary production varied between seasons and years. Major differences were related to anomalous conditions in 1997 and 1998. The density of euphausiids was higher at the front and offshore of the front during summer, but there were no differences among regions during spring. Foraging shearwaters aggregated in high densities at the front during summer, but foraged close to shore during spring. At the front, shearwaters foraged on euphausiids Thysanoessa raschii and T. inermis as expected, and on copepods that accumulated in the area. The proportion of zooplankton consumed at the front decreased from summer 1997 to summer 1999, while consumption of sandlance Ammodytes hexapterus at this feature increased. Our results show that, during summer, the inner front supports aggregations of euphausiids and their seabird predators. The means by which the frontal system supports enhanced production and the subsequent trophic transfers is dependent on the availability of nutrients at depth in the frontal region and the aggregation of small zooplankton organisms in this feature.
\end{abstract}

KEY WORDS: Short-tailed shearwater - Puffinus tenuirostris · Euphausiids · Thysanoessa raschii · Thysanoessa inermis · Seabird foraging · Fronts · Bering Sea

Resale or republication not permitted without written consent of the publisher

\section{INTRODUCTION}

Seabirds and other higher trophic-level organisms are known to aggregate and make use of the enhanced production that usually occurs at tidal fronts (Pingree et al. 1974, Schneider 1982, Hunt et al. 1996, 1999c, Begg \& Reid 1997, Durazo et al. 1998). Increased production at fronts may not always be the case, and at least 1 front has been shown to have decreased production and not to be important for the successful foraging of seabirds and other predators (Caldeira et al. 2001). The purpose of this paper was to test the hypothesis that foraging short-tailed shearwaters Puffinus tenuirostris aggregate at the inner front of the
SE Bering Sea to prey on euphausiids aggregating to feed on the enhanced primary production expected to occur in this feature during summer.

Millions of short-tailed shearwaters migrate each year across the equator from their breeding grounds in southern Australia and Tasmania to winter in the North Pacific and the Bering Sea (Marshall \& Serventy 1956, Warham 1990). Birds arrive in the SE Bering Sea early in the spring, and by mid-May (Schneider \& Shuntov 1993, Shuntov 1993) thousands are found in Bristol Bay (see Fig. 1), where they are the most abundant seabird during summer (Hunt et al. 1981b). Shorttailed shearwaters are often associated with areas of strong tidal shears (Schneider \& Shuntov 1993). This 
species congregates in high numbers in the vicinity of the $50 \mathrm{~m}$ isobath (Hunt et al. 1981b, Schneider \& Shuntov 1993), which corresponds to the location of a tidal front (i.e. the inner front; Schumacher et al. 1979, Coachman 1986, Stabeno et al. 2001, Kachel et al. 2002). In the past, shearwaters in Bristol Bay foraged primarily on the euphausiids Thysanoessa raschii and T. inermis (Ogi et al. 1980, Hunt et al. 1981a, 1996, 2002, Schneider et al. 1986), which are abundant in this area (Vidal \& Smith 1986, Smith 1991, Coyle \& Pinchuk 2002a). The predominately coastal distribution of short-tailed shearwaters in Bristol Bay and the SE Bering Sea has been hypothesized to be the result of birds being attracted to large surface concentrations of euphausiids feeding on phytoplankton patches associated with the inner front (Hunt et al. 1996).

The inner front is a structural front that separates the stratified waters of the middle domain from the mixed waters of the coastal domain of the SE Bering Sea (Kachel et al. 2002). The stratification of middle domain water is maintained by heating and wind-mixing of the top layer and tidal-mixing of the bottom layer (Iverson et al. 1979a, Kachel et al. 2002). Surface and tidalmixing depths converge shoreward of the $50 \mathrm{~m}$ isobath, producing a well-mixed water mass where bottom waters are constantly stirred upwards (Iverson et al. 1979a, Kachel et al. 2002).

The abundance of nutrients and incident radiation over the SE Bering Sea supports high levels of primary production early in the spring (Iverson et al. 1979a,b). After the spring bloom, nutrients become limiting and the phytoplankton maximum occurs at $30 \mathrm{~m}$ where a chlorophyll maximum persists into the fall (Iverson et al. 1979a, Kachel et al. 2002). Early in summer, nutrients are usually exhausted in the upper mixed layer, although a large reservoir exists below it (Kachel et al. 2002). Nutrients are replenished in the euphotic zone by intense storms that break down the stratification of the water (Iverson et al. 1974, Sambroto et al. 1986, Kachel et al. 2002), and tidally induced vertical mixing at the inner front that supports local phytoplankton blooms in the summer (Iverson et al. 1974, Sambroto et al. 1986, Hunt et al. 1996, Kachel et al. 2002).

Tidal currents over shallow topography provide a continuous source of nutrients that are mixed back into the water column and can stimulate phytoplankton production (Holligan 1981, Mann \& Lazier 1996). Tidally generated fronts, such as the inner front, separate well-stratified waters from well-mixed waters over shallow continental shelves during summer (Holligan 1981, Mann \& Lazier 1996, Maguer et al. 2000). Offshore of these fronts, primary production nearly ceases after nutrients are depleted by the spring bloom (Pingree et al. 1976). Inshore of these fronts, a nutrientrich system develops if the well-mixed water is suffi- ciently deep, and light-limited phytoplankton never fully depletes its nutrients (Holligan 1981). A nutrientpoor system, such as that in the Bering Sea, develops if the well-mixed water is shallow and nutrients are depleted by the phytoplankton (Holligan 1981, Walsh \& McRoy 1986). Characteristically, there is a higher biomass of phytoplankton at tidal fronts than in wellstratified or well-mixed waters (Pingree et al. 1975, Holligan 1981, Maguer et al. 2000). Vertical mixing processes and the relative stabilization of the water column offshore of the front maintain favorable conditions for maximum phytoplankton growth rates in these areas (Pingree et al. 1974, Fogg 1984, Fogg et al. 1985, Le Fevre 1986). The high productivity characteristic of tidal fronts is reflected by an abundance of higher trophic-level organisms such as predatory fishes, seabirds and marine mammals (Pingree et al. 1974, Schneider 1982, Hunt et al. 1996, 1999c, Begg \& Reid 1997, Durazo et al. 1998).

In this study, we investigated the role of the inner front of the SE Bering Sea as a feature of the marine environment important for successful foraging by shearwaters. We predicted that foraging short-tailed shearwaters would aggregate at the inner front of the SE Bering Sea to prey on euphausiids feeding there on the enhanced primary production that is expected to occur in this physical feature subsequent to the spring bloom. To test this hypothesis, we measured the distribution and abundance of shearwaters, euphausiids and primary production at and away from the inner front of the SE Bering Sea.

\section{MATERIALS AND METHODS}

Study area. We studied the distribution of foraging short-tailed shearwaters relative to the inner front of the SE Bering Sea by conducting multiple crossings of the front in 4 predetermined grids located off Slime Bank, Port Moller, Cape Newenham and Nunivak Island (Fig. 1). Grid areas consisted of 1 to 5 transect lines running perpendicular to the bathymetry from nearshore to beyond the $50 \mathrm{~m}$ isobath. Cruises were carried out in late spring (May to June), and late summer/early fall (July to September), during 3 consecutive years (1997 to 1999). During each cruise, the physical structure of the water, primary productivity, euphausiid distribution and shearwater distribution and diet were determined.

A recognizable inner front was found in $41 \%$ out of 83 CTD transects occupied during the inner front project (Kachel et al. 2002). In these cases the location of the inner front was taken from Kachel et al. (2002), who defined the inner edge of the front as 'the seawardmost location where the maximum gradient in 


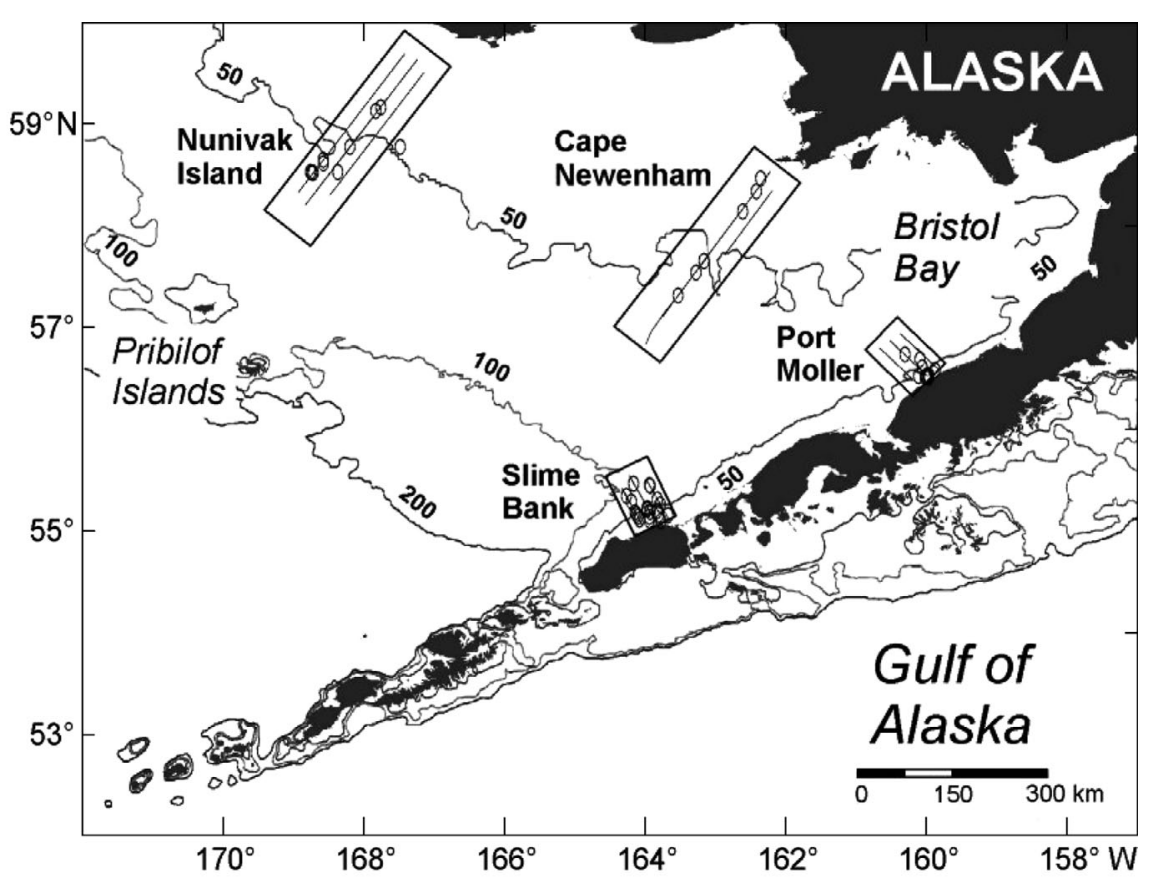

Fig. 1. SE Bering Sea, showing location of study areas at Nunivak Island, Cape Newenham, Port Moller and Slime Bank. Transect lines surveyed in each grid area are shown; (0) locations where shearwaters Puffinus tenuirostris were collected for stomach-content analysis surements, chlorophyll profiles, and light attenuation in the water column using a numerical integration model (Zeeman \& Jensen 1990a,b). Daily in situ production was estimated using chlorophyll-specific production as a function of light from the incubations plus in situ measurements of irradiance and chlorophyll (Zeeman 1992). Photosynthesis versus irradiance functions and chlorophyll a determinations were obtained as described by Stockwell et al. (2001). In situ experiments consisted of duplicate light and dark bottles, identical to those used in the incubator experiment, suspended in groups of 4 at 6 depths from the surface to $40 \mathrm{~m}$. These bottles contained 5 to $10 \mu \mathrm{Ci}$ of ${ }^{14} \mathrm{C}$. Incubations proceeded for $1 \mathrm{~h}$ or less, and then the bottle string was retrieved and samples filtered and counted in a manner similar to that used for the incubator samples. The in situ measurements were used as independent measurements to verify the incubator estimates.

temperature by depth was less than $0.05^{\circ} \mathrm{C} \mathrm{m}^{-1}$ and the outer edge of front as the location where the maximum gradient in temperature by depth becomes less than one-half the greatest value observed on that grid of stations and less than $1^{\circ} \mathrm{C} \mathrm{m}^{-1}$. The mean distance from the coast and depth of the outer and inner edges of the inner front in each grid area are shown in Table 1. We used both the mean location and the precise location of the front to divide transects into regions (i.e. inshore, mean front, offshore) and to study the importance of processes at the front relative to the nearby non-frontal regions.

Primary productivity. Primary production was measured using ${ }^{14} \mathrm{C}$ uptake rates from a combination of incubator and in situ experiments. Water samples were collected using Niskin bottles at multiple depths. Primary productivity rates were estimated using ${ }^{14} \mathrm{C}$-labelled bicarbonate. Incubations were carried out in triplicate under controlled temperature and different light intensities (Zeeman \& Jensen 1990a,b). Primary production rates were calculated using light-dark counts, and normalized to chlorophyll a concentrations (Parsons et al. 1984). Water-column productivity rates were estimated from the uptake mea-
Table 1. Mean $( \pm \mathrm{SD})$ distance from coast and depth of outer and inner edges of inner front of SE Bering Sea. Numbers in parentheses: number of times edges of inner front were observed during transect runs

\begin{tabular}{|c|c|c|c|c|}
\hline \multirow{2}{*}{ Area } & \multicolumn{2}{|c|}{ Outer edge } & \multicolumn{2}{|c|}{ Inner edge } \\
\hline & $\begin{array}{l}\text { Distance } \\
(\mathrm{km})\end{array}$ & $\begin{array}{l}\text { Depth } \\
\text { (m) }\end{array}$ & $\begin{array}{l}\text { Distance } \\
(\mathrm{km})\end{array}$ & $\begin{array}{l}\text { Depth } \\
\text { (m) }\end{array}$ \\
\hline Slime Bank & $26 \pm 11(15)$ & $73 \pm 17(15)$ & $15 \pm 12(12)$ & $48 \pm 17(12)$ \\
\hline Port Moller & $29 \pm 9$ & $56 \pm 8$ & $7(1)$ & $24(1)$ \\
\hline Cape Newenham & $146 \pm 22(9)$ & $50 \pm 4$ & $110 \pm 49(9)$ & $44 \pm 6 \quad(9)$ \\
\hline Nunivak Island & $169 \pm 14(25)$ & $54 \pm 5$ & $132 \pm 33(16)$ & $44 \pm 7$ \\
\hline
\end{tabular}


determined for every $180 \mathrm{~m}$ interval in 1997, and for 45 m intervals in 1998 and 1999, at vertical intervals of 1 to $2 \mathrm{~m}$. We transformed densities into biomass and integrated it from the bottom to the surface, producing estimates of the total amount of euphausiids in the water column.

Distribution of shearwaters. Counts of shearwaters and other birds were made from the bridge of the RV 'Alpha Helix' (eye level $=7.7 \mathrm{~m}$ above the sea surface) while the ship was underway. Vessel speed varied from about $11 \mathrm{~km} \mathrm{~h}^{-1}$ while conducting acoustic surveys to about $19 \mathrm{~km} \mathrm{~h}^{-1}$ when cruising between oceanographic stations. Birds were counted continuously during daylight hours in a $300 \mathrm{~m}$ arc from directly ahead of the vessel to $90^{\circ}$ off the side with best visibility (i.e. lowest glare) and logged into a portable computer. Each separate entry in the computer of 1 or more birds was considered a flock. When continuous lines of flying shearwaters (>1000 individuals) were encountered crossing the bow of the vessel, observers switched to a snapshot method of counting birds to minimize the overestimate of numbers present (Tasker et al. 1984). Shearwater behaviors were recorded as flying, sitting on the water, and feeding; for the purpose of this analysis, we assumed that birds sitting on the water had previously fed in the vicinity of where they were resting.

Seabird counts were carried out during CTD and acoustic transects, and unless one of the transects was at night, a minimum of 2 seabird data sets existed for each transect line. Seabird counts during CTD transects were interrupted every $25 \mathrm{~min}$, for about $30 \mathrm{~min}$ after arriving at oceanographic stations. Acoustic transects were carried out without interruption and may provide a better representation of seabird distribution along the transect lines. Seabird counts from CTD transects were included when counts from acoustic transects were not available (i.e. transects were done at night). Seabird density (birds $\mathrm{km}^{-2}$ ) was determined by dividing the number of seabirds and flocks by the number of kilometers surveyed.

Diet composition of shearwaters. We determined the diet composition of shearwaters by shooting 3 to 8 birds per flock from flocks of birds that were foraging within each grid area. We limited our collections to foraging birds so that we could be certain that the birds had obtained their prey near to the place at which we collected them. Upon collection, proventriculus contents were removed, weighed and preserved in $80 \%$ ethanol. Wet weight of alcohol-preserved specimens, their displacement volume, and direct counts were used to determine the diet of individual birds, as described in Hunt et al. (2002). We assumed that individuals shot at the same location were not independent, and estimated diet composition by averaging the prey- type volumes and prey-item numbers for birds from the same collection. We determined the proportion of prey types by volume and the proportion of zooplankton organisms by number for each bird collection. We transformed all data into proportions to avoid the possibility that a few individual birds with large amounts of one particular prey would disproportionately influence the assessment of overall diet composition.

Data analysis. We divided all transects into regions, determined by the location of the edges of the front, and calculated the euphausiid biomass and number of shearwaters in each region to examine whether prey and birds were being attracted to the front. We used (1) the mean distance from the coast to the outer and inner edges of the inner front to divide all transects into regions (i.e. mean frontal region, MFR), and (2) the exact location of the edges of the front (Kachel et al. 2002) to divide the corresponding transects into regions (i.e. precisely defined fronts, PDF). The latter include seabird surveys conducted while towing acoustic equipment along the same transect within $2 \mathrm{~d}$ of the date when the exact location of the front was determined. In these cases we assumed that oceanographic conditions and the location of the front had not changed. We also assigned primary production estimates and bird-diet collections to regions determined by the mean location of the front (Table 1).

We used Kruskal-Wallis 1-way analysis of variance to compare the rate of primary production between regions determined by the mean location of the front. We used the Wilcoxon matched-pairs signed-ranks test to compare the density of euphausiids and seabirds among inshore, front and offshore regions. We used the euphausiid biomass in a $1 \mathrm{~m}^{2}$ column of water and the number of shearwaters feeding and sitting on the water in $1 \mathrm{~km}^{2}$, averaged over the whole length of the region, as the measure of euphausiid and shearwater density, respectively. We used regression analysis to examine whether euphausiids (log-transformed) aggregate in larger densities at the narrower fronts, and Kruskal-Wallis 1-way analysis of variance and MannWhitney $U$-tests to compare distance from the coast of large aggregations of foraging shearwaters and the diet composition of shearwaters in habitat regions determined by the location of the front. We sampled the location of the large aggregations of shearwaters by sorting all $1 \mathrm{~km}$ bins within each grid area by their number of shearwaters, and separated all bins with highest values needed to account for $90 \%$ of the total number of shearwaters observed each season, this comprised 133 of 5701 bins in spring and 131 of 4333 bins in summer.

We used the utilization test to examine the significance of euphausiid and shearwater aggregations in 3 habitat regions - offshore of the front, within the 
frontal area and inshore of the front (Haney \& Solow 1992). We compared the non-overlapping transect regions previously determined using the MFR and PDF. The width of the frontal region was determined by Kachel et al. (2002). The length of the non-frontal region varied according to the location and length of transects. Assuming a uniform distribution of shearwaters along each transect, we calculated an expected value for the number of shearwaters and flocks of shearwaters that should have occurred within each transect region. This expected value was based on the total number of shearwaters and flocks of shearwaters counted along the transect and the amount of survey effort (k surveyed) spent in each region. Observed values were compared to expected values and 95\% confidence intervals were constructed according to the methods of $\mathrm{Neu}$ et al. (1974) for the observed proportions of birds for a Type I error rate of $\alpha=0.05$. We conducted these analyses on data pooled by season, year and grid area.

We used a permutation analysis (Riehle et al. 2001) to determine the location of the significant aggregations of euphausiids along the transects, and determined the observed density of euphausiids within a $5 \mathrm{~km}$ sliding window that moved throughout the series of data. Expected density of euphausiids and confidence intervals were obtained by a permutation testing procedure. The mean, variance and 95\% confidence intervals in the expected density of euphausiids were calculated over 500 random permutations of the order of 500 bins sampled from the remaining length of the transect.

\section{RESULTS}

\section{Late spring conditions}

Neither enhanced primary production nor euphausiid aggregations were found at the inner front during late spring (Table 2). The rate of primary production at the mean front was not significantly different than elsewhere along the transect (Kruskall-Wallis statistic = $0.754, \mathrm{df}=2, \mathrm{n}=52, \mathrm{p}=0.686)$. Although the density of euphausiids at the MFR was significantly higher than elsewhere along-transect in 10 out of 21 (48\%) transects, and at the PDF in 9 out of $11(82 \%)$ fronts (uti-
Table 2. Mean $( \pm \mathrm{SE})$ primary production, density of euphausiids (Thysanoessa spp.) and abundance of shearwaters Puffinus tenuirostris relative to inner front of Sea, analyzed using mean frontal regions or precisely defined fronts.

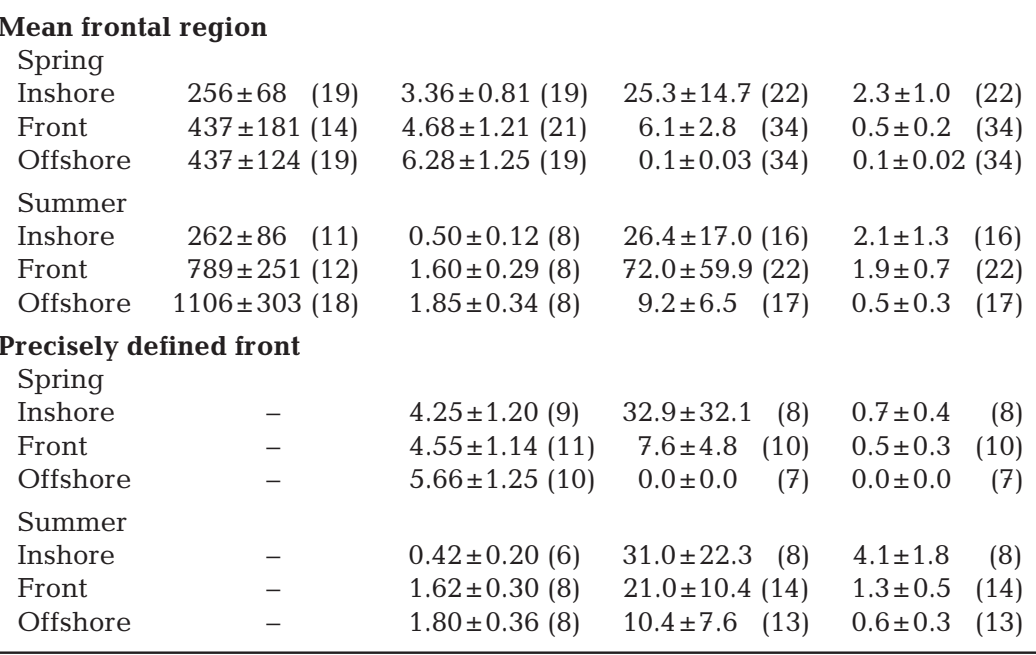

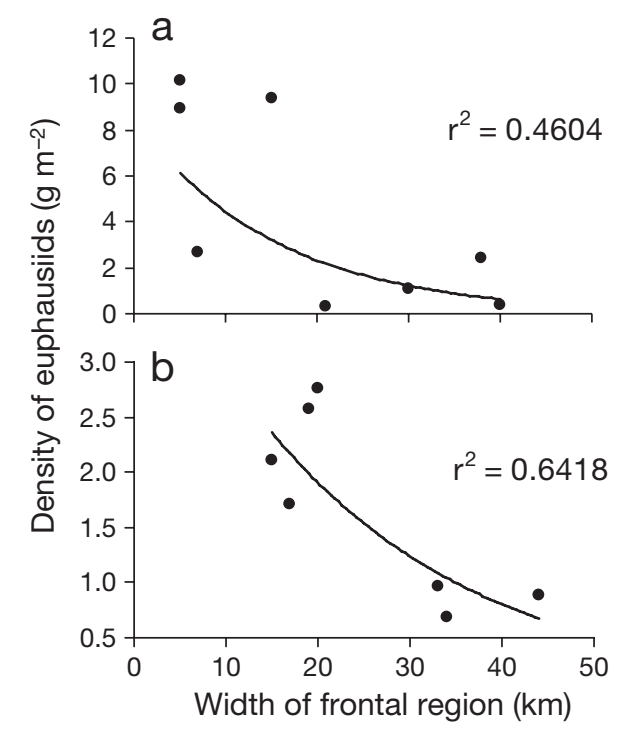

Fig. 2. Thysanoessa spp. Density as function of width of precisely defined fronts (PDF) identified in (a) spring and (b) summer cruises

lization test, $\mathrm{p}<0.05)$, no statistical differences in density of euphausiids were found between regions in the spring, whether we used MFR or PDF for analyses (Wilcoxon matched-pairs signed-ranks statistic, p > 0.05). The density of euphausiids was not significantly higher in the narrower PDF (Fig. 2a, $\mathrm{r}^{2}=0.460, F=5.119$, $p=0.064, n=8)$. Significant aggregations of euphausi- 

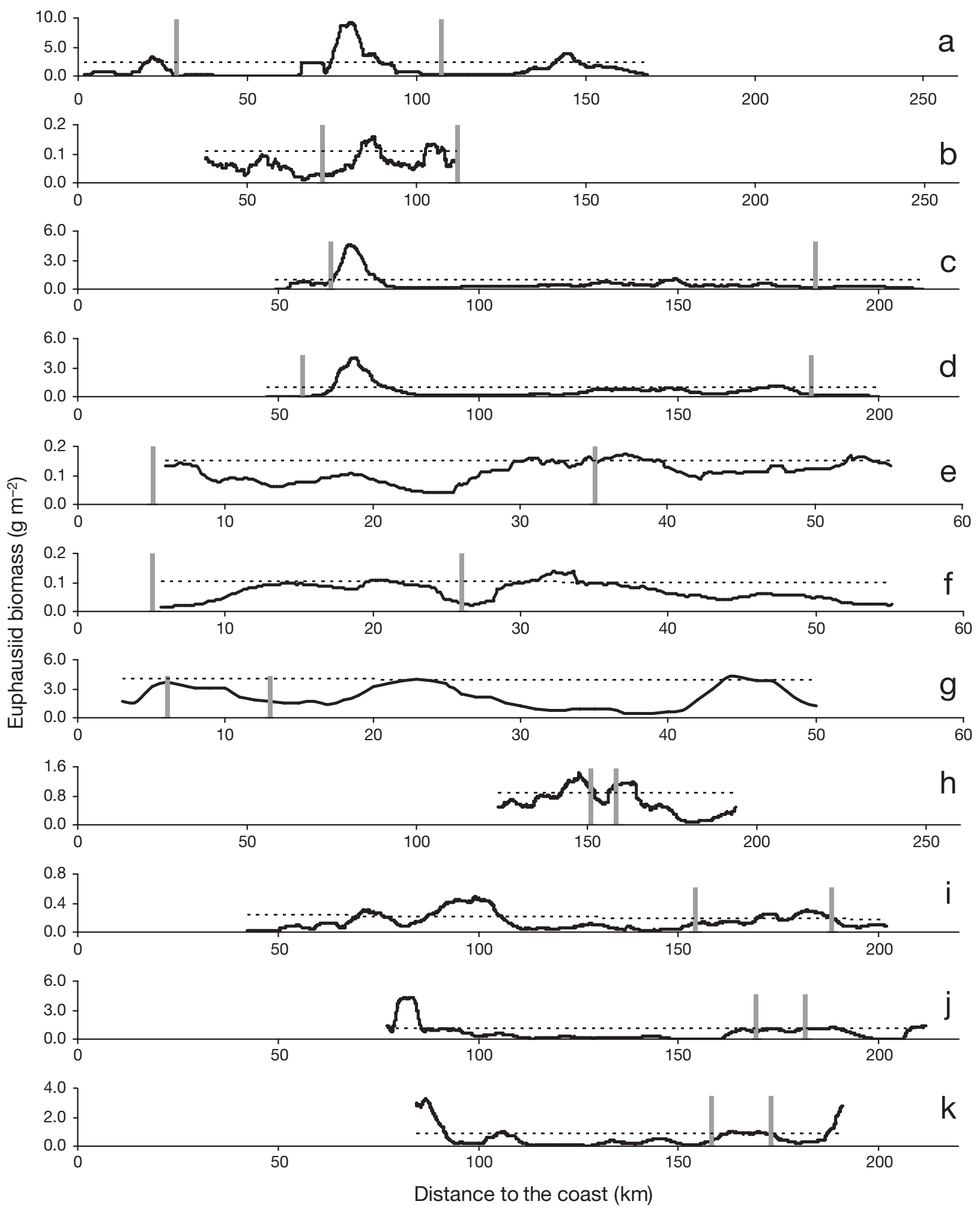

Fig. 3. Thysanoessa spp. Distribution of biomass in spring of $(\mathrm{a}-\mathrm{g})$ 1997, (h,i) 1998, and $(\mathrm{j}, \mathrm{k}) 1999$ along transects in which inner and outer edges of frontal region (as defined by Kachel et al. 2002) were observed. Shaded bars represent inner (on left) and outer (on right) edges of front; dotted line: $95 \%$ confidence interval (data above this line are considered significant aggregations). (a) Cape Newenham C; (b) Cape Newenham E; (c) Nunivak Island C2; (d) Nunivak Island E; (e) Port Moller A; (f) Port Moller C; (g) Slime Bank $C_{i}(\mathrm{~h})$ Cape Newenham $C_{i}(\mathrm{i})$ Nunivak Island $C_{i}(\mathrm{j})$ Nunivak Island $C_{i}(\mathrm{k})$ Nunivak Island E 
ids occurred within the PDF in 5 out of 11 transect lines $(45 \%)$; no clear spatial pattern in the location of these aggregations was found (Fig. 3).

Aggregations of foraging short-tailed shearwaters were found inshore of the inner front during late spring (Table 2). The mean density of shearwaters feeding and sitting on the water inshore of the MFR was 4 times the density of shearwaters found foraging at the MFR. The number of birds and flocks at the MFR was significantly higher than elsewhere along transect in 24 and $22 \%$ of the 41 transects and at the PDF in $20 \%$ of the 10 fronts, respectively (utilization test, $\mathrm{p}<0.05$ ). No statistical differences in density of foraging shearwaters were found between the inshore and the MFR (Wilcoxon matched-pairs signed-ranks statistic $=0.314$, $\mathrm{n}=41, \mathrm{p}=0.754$ ), and significantly higher densities of foraging shearwaters were found inshore and at the MFR than offshore of this feature (Wilcoxon matchedpairs signed-ranks statistic, $\mathrm{n}=41, \mathrm{p}<0.05$ ). The numbers of flocks of shearwaters showed similar patterns (Wilcoxon matched-pairs signed-ranks statistic, $\mathrm{n}=41$, $\mathrm{p}<0.05)$.

Zooplankton, particularly euphausiids, were the main prey consumed by short-tailed shearwaters foraging in the inner domain of the SE Bering Sea during late spring. Zooplankton represented, on average, 75\% by volume of the prey consumed in spring, the remainder of their prey was fishes. The proportion of zooplankton in the diet decreased from $100 \%$ by volume in spring 1997 to $50 \%$ by volume in spring 1999 (Fig. 4a); conversely, the proportion of sandlance Ammodytes hexapterus increased during the same period. The most important zooplankton consumed were euphausiids, representing $95 \%$ by number of the items consumed (Fig. 4b). The euphausiid Thysanoessa raschii was the most common prey item found in the diet, and its consumption decreased from $96 \%$ by number in spring 1997 to $38 \%$ in spring 1999 . The proportion of $T$. inermis in the diet increased over the same period to $38 \%$ by number during spring 1999.

\section{Late summer and early fall conditions}

We found enhanced primary production at the inner front and offshore of the front during late summer and early fall (Table 2). However, the mean rate of primary production at the MFR was not significantly different than elsewhere along the transect (Kruskall-Wallis statistic $=4.143, \mathrm{df}=2, \mathrm{n}=41, \mathrm{p}=0.126$ ). Primary production rates at the MFR were intermediate compared to the low production observed inshore of the front and the high production observed offshore of this feature. Significant differences in the rate of primary production between years confounded our results (Kruskall-
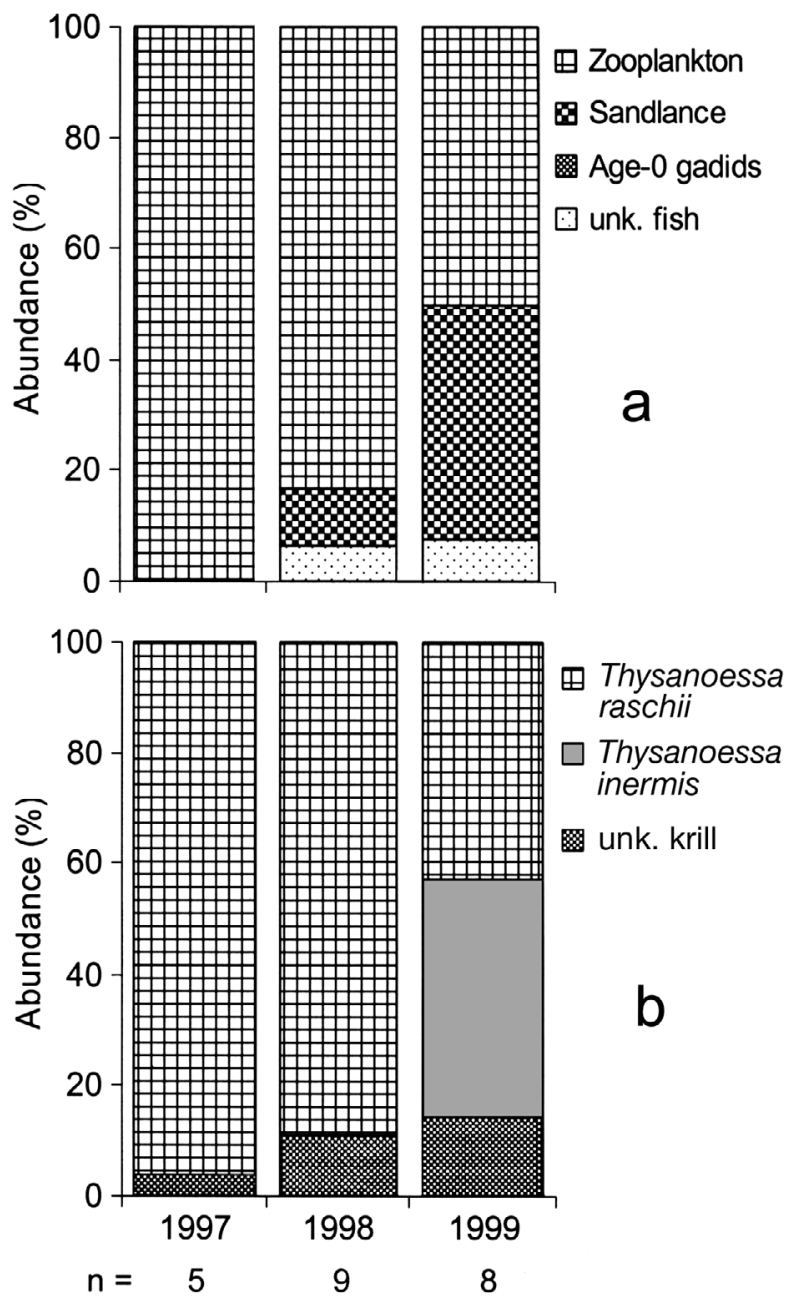

Fig. 4. Puffinus tenuirostris. Diet composition in spring. (a) Relative consumption of major prey types (by volume); (b) consumption of main zooplankton organisms (by number). n: sample size for each year; unk: unknown (i.e. unidentified)

Wallis statistic $=26.045, \mathrm{df}=2, \mathrm{n}=41, \mathrm{p}<0.001$ ). In the summers of 1997 and 1998, no significant differences in the rate of primary production were found between regions (Kruskall-Wallis statistic, $\mathrm{df}=2, \mathrm{p}>0.05$ ); in summer 1999, the rate of primary production was significantly higher at the front and offshore of the front than inshore of this feature (Kruskall-Wallis statistic = 8.697, $\mathrm{df}=2, \mathrm{n}=16, \mathrm{p}=0.013$ ).

Aggregations of euphausiids were found at the inner front and offshore of the front during late summer and early fall (Table 2). The density of euphausiids at the MFR was significantly higher than elsewhere alongtransect in 6 out of $8(75 \%)$ transects surveyed, whether we used MFR or PDF for analyses (utilization test, $p<0.05)$. The density of euphausiids inshore of the front was significantly lower than in the MFR and offshore regions (Wilcoxon matched-pairs signed- 
ranks statistic, $\mathrm{n}=8, \mathrm{p}<0.05$ ) and there were no significant differences in density of euphausiids between the MFR and the offshore region (Wilcoxon matched-pairs signed-ranks statistic $=0.280, \mathrm{n}=8, \mathrm{p}=0.779$ ). The density of euphausiids was significantly higher in the narrower PDF (Fig. 2b, $r^{2}=0.713, F=12.420, p=0.017$, $\mathrm{n}=7$ ). Aggregations of euphausiids were found near the offshore end of the PDF in 6 out of the 8 transects for which acoustic data were available (Fig. 5).

Foraging short-tailed shearwaters aggregated at the inner front of the SE Bering Sea during late summer and early fall (Table 2). The mean density of shearwaters feeding and sitting on the water at the MFR was about 3 times the density of shearwaters foraging inshore of the front. The number of birds and flocks was significantly higher at the MFR in 25 and $17 \%$ of the 24 transects and at the PDF in 47 and $20 \%$ of the 15 fronts, respectively (utilization test, $\mathrm{p}<0.05$ ). There were no statistically significant differences in density of foraging shearwaters between the inshore and the MFR (Wilcoxon matched-pairs signed-ranks statistic $=$ $-6.222, \mathrm{n}=24, \mathrm{p}=0.539)$. The density of foraging
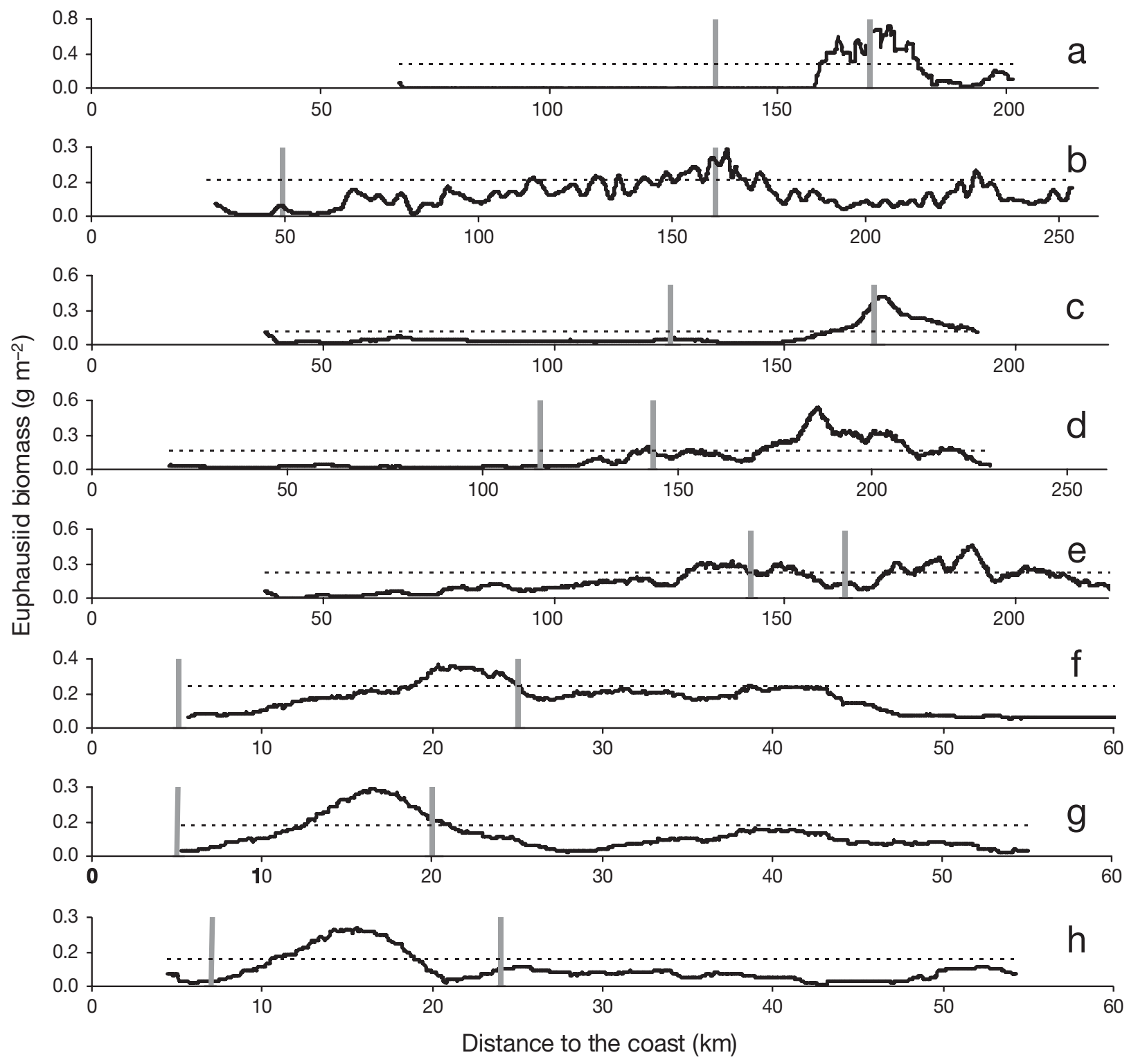

Fig. 5. Thysanoessa spp. Distribution of biomass in summer of (a) 1997, (b,c) 1998 and (d-h) 1999 along transects in which inner and outer edges of frontal region (as defined by Kachel et al. 2002) were observed. (a) Nunivak Island C2; (b) Cape Newenham C2; (c) Nunivak Island C2; (d) Cape Newenham C1; (e) Nunivak Island C1; (f) Port Moller A; (g) Port Moller C; (h) Port Moller E. Further details in Fig. 3 legend 
shearwaters at the MFR was 8 times that of birds foraging offshore of the front and this difference was significant (Wilcoxon matched-pairs signed-ranks statistic $=$ $-1.956, \mathrm{n}=24, \mathrm{p}=0.05)$. The number of flocks of shearwaters showed patterns that were similar to that of densities among regions (Wilcoxon matched-pairs signed-ranks statistic, $\mathrm{n}=24, \mathrm{p}<0.05)$.

Short-tailed shearwaters foraged at greater distances from the coast during late summer and early fall (Fig. 6). The seasonal differences in distance from the coast of foraging aggregations were statistically significant in Nunivak Island, Cape Newenham and Slime
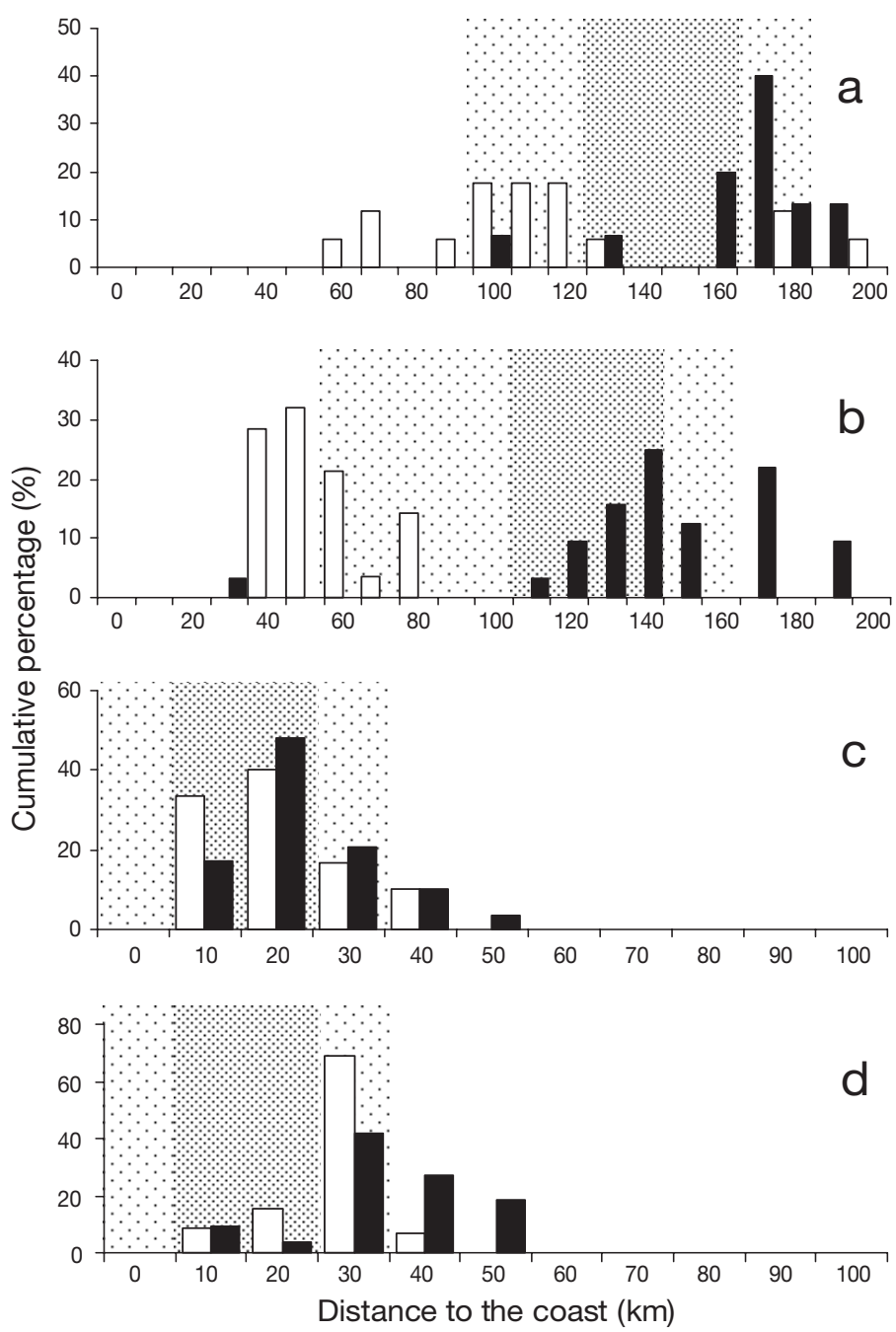

Fig. 6. Puffinus tenuirostris. Distance to coast of large aggregations ( $90 \%$ of total foraging seabirds) in spring (open bars) and summer (black bars). Dark-shaded area: extent of mean frontal region; light-shaded area: extent of maximum frontal region which includes $1 \mathrm{SD}$ added at each edge (Table 1). (a) Nunivak Island $\left(\mathrm{n}_{\text {spring }}=17, \mathrm{n}_{\text {summer }}=15\right)$; (b) Cape Nevwenham $\left(\mathrm{n}_{\text {spring }}=28, \mathrm{n}_{\text {summer }}=32\right)$; (c) Port Moller $\left(\mathrm{n}_{\text {spring }}=30\right.$; $\left.\mathrm{n}_{\text {summer }}=29\right) ;(\mathrm{d})$ Slime Bank $\left(\mathrm{n}_{\text {spring }}=58 ; \mathrm{n}_{\text {summer }}=55\right)$
Bank (Mann-Whitney U-test, $\mathrm{p}<0.05$ ), where shorttailed shearwaters foraged closer to the coast in spring and away from the coast in the summer. The location of foraging aggregations in summer coincided with the MFR, with a peak in bird numbers near the outer edge of the front (Fig. 6).

The use of the inner front by foraging short-tailed shearwaters during late summer and early fall varied greatly between years. There were more shearwaters foraging at the MFR than expected by chance in 1997 and 1999 and less than expected in late summer and early fall 1998 (utilization test, $\mathrm{p}<0.05$ ). There were no differences in the number of flocks of shearwaters between regions in 1997 and 1999, and significantly fewer flocks foraging at the front in 1998 (utilization test, $\mathrm{p}>0.05$ ).

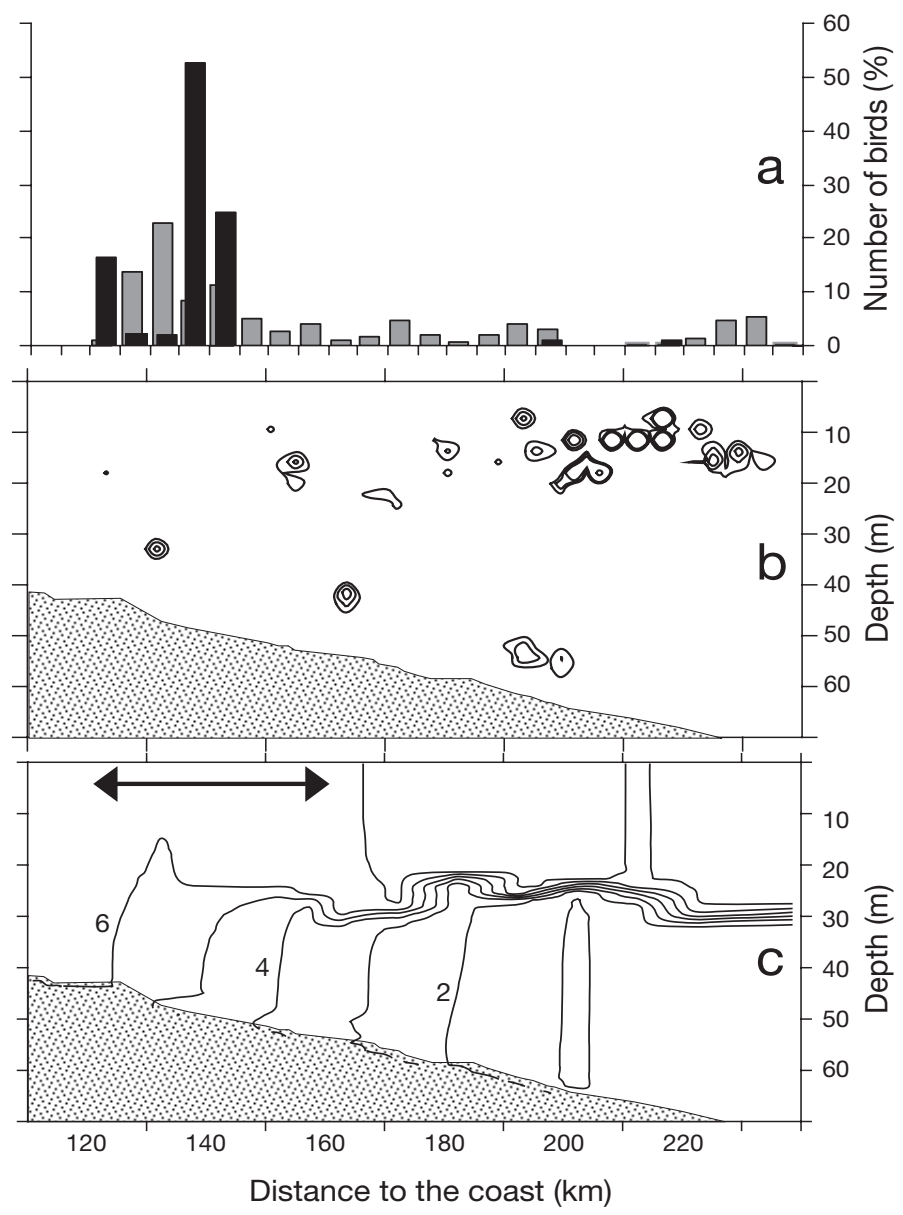

Fig. 7. (a) Distribution of flying (light bars) and foraging (dark bars) Puffinus tenuirostris as proportion of total number displaying each behavior; (b) distribution of acoustically estimated biomass of euphausiids (Thysanoessa spp.) >100 mg $\mathrm{m}^{-3}$; (c) temperature contours $\left({ }^{\circ} \mathrm{C}\right.$ ) along Transect $\mathrm{C}$ off Cape Newenham in summer 1999, arrow indicates precise position of front (after Kachel et al. 2002) 
We chose 2 examples of foraging shearwaters associated with the inner front-in summer 1999 in Cape Newenham and Port Moller. In Cape Newenham we found more shearwaters than expected by chance foraging at the inner front (utilization test, p < 0.05); $95 \%$ percent of the birds and $80 \%$ of the flocks were foraging in this area (Fig. 7). We found birds flying all along the $130 \mathrm{~km}$ transect surveyed; $70 \%$ of them were located at the front. The density of euphausiids in this particular transect was higher offshore of the front (acoustically determined biomass, $\mathrm{ADB}=2.6 \mathrm{~g} \mathrm{~m}^{-2}$ ) than in the frontal region $\left(\mathrm{ADB}=1.0 \mathrm{~g} \mathrm{~m}^{-2}\right)$. However, the stratified waters offshore of the front were green or milky-green inside the densest part of the cocco-
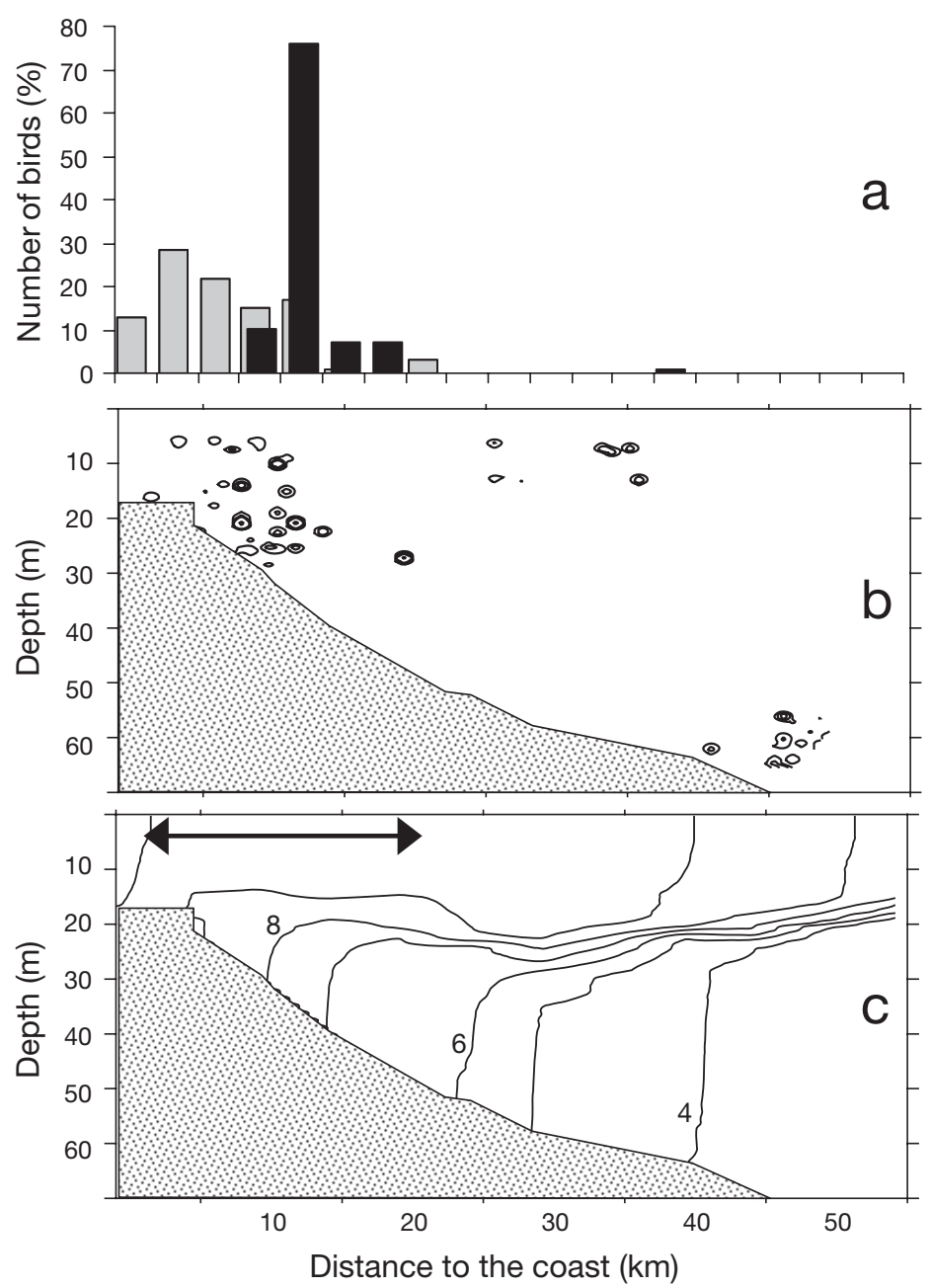

Fig. 8. (a) Distribution of flying (light bars) and foraging (dark bars) Puffinus tenuirostris as proportion of total number displaying each behavior; (b) distribution of acoustically estimated biomass of euphausiids (Thysanoessa spp.) >100 mg $\mathrm{m}^{-3}$; (c) temperature contours $\left({ }^{\circ} \mathrm{C}\right)$ along Transect $\mathrm{E}$ off Port Moller in summer 1999; arrow indicates precise position of front (after Kachel et al. 2002) lithophore bloom (Stockwell et al. 2001). In Port Moller, the number of shearwaters and flocks of shearwaters foraging at the inner front were also higher than expected by chance (utilization test, p < 0.05) (Fig. 8). All birds and flocks of foraging birds were at the front. The density of euphausiids in this case was higher at the front $\left(\mathrm{ADB}=1.7 \mathrm{~g} \mathrm{~m}^{-2}\right)$ than offshore of the front $\left(\mathrm{ADB}=0.7 \mathrm{~g} \mathrm{~m}^{-2}\right)$.

Zooplankton, particularly euphausiids and crab larvae, were the main prey consumed by short-tailed shearwaters foraging at the SE Bering Sea during late summer and early fall. Zooplankton represented, on average, $70 \%$ by volume of the prey consumed, the remainder was fishes. The proportion of zooplankton in the diet decreased from $100 \%$ by volume in late summer and early fall 1997 to about $40 \%$ by volume of prey consumed in the same period in 1998 and 1999
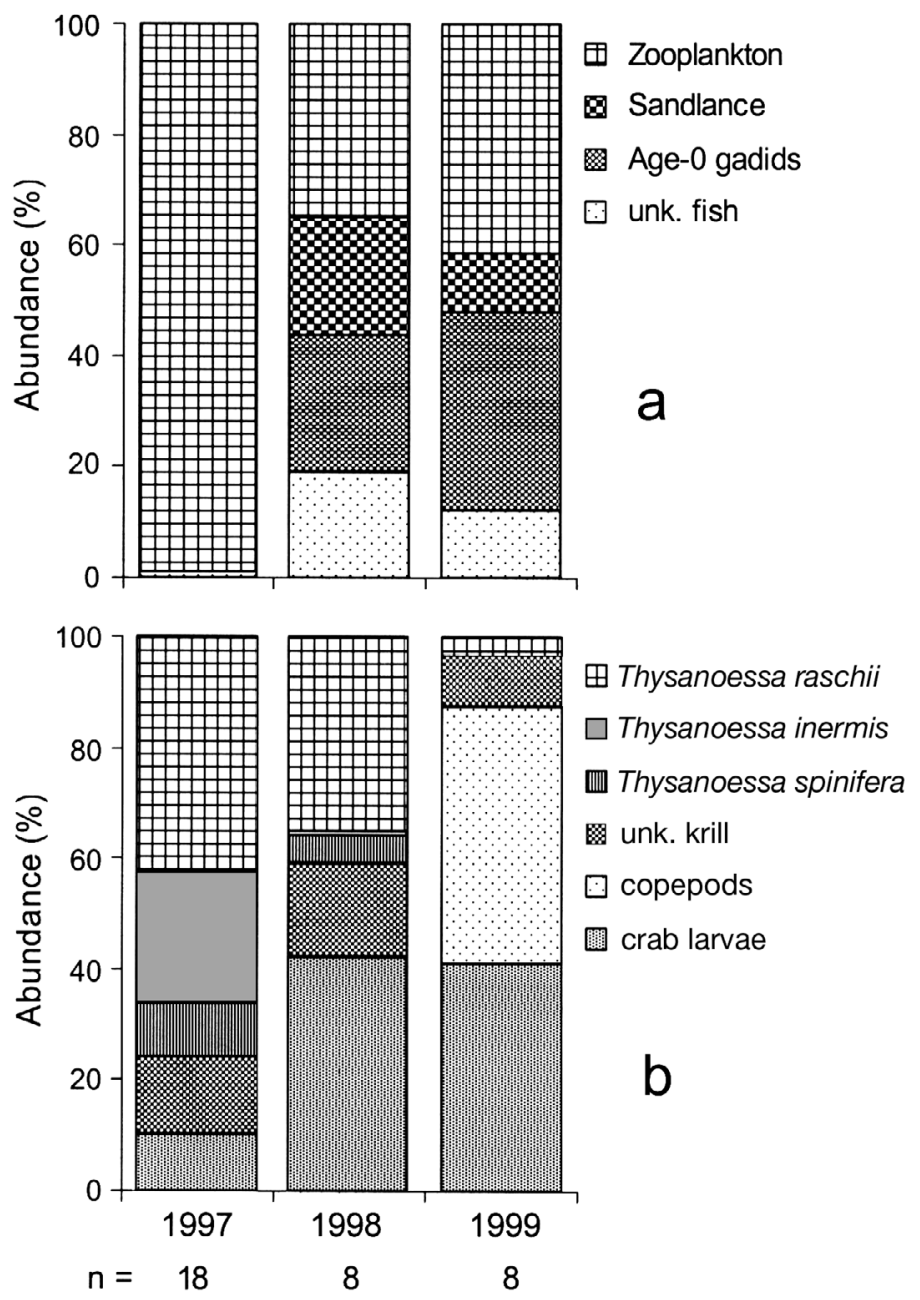

Fig. 9. Puffinus tenuirostris. Diet composition in summer. (a) Relative consumption of major prey types (by volume); (b) consumption of main zooplankton organisms (by number). $\mathrm{n}$ : sample size for each year 
(Fig. 9a), the proportion of sandlance and Age-0 gadids (most probably walleye pollock Theragra chalcograma) increased during the same period. The most important zooplankton were the euphausiid Thysanoessa raschii (with about $40 \%$ by number consumed in summer 1997 and 1998), crab larvae (about $40 \%$ in summer 1998 and 1999) and copepods (about 50\% in summer 1999) (Fig. 9b).

\section{Diet of shearwaters in relation to inner front}

Zooplankton was the main prey consumed by shorttailed shearwaters foraging at the inner front (Fig. 10a), representing 82 to $93 \%$ by volume of the pooled sample of consumed prey, depending on whether we used the MFR or the PDF for analyses, respectively. However, the proportion of zooplankton in the diet was not significantly higher at the MFR (Kruskall-Wallis statistic $=2.125, \mathrm{df}=2, \mathrm{n}=56, \mathrm{p}=0.346$ ) or at the PDF (Kruskall-Wallis statistic $=1.209, \mathrm{df}=2, \mathrm{n}=16$, $p=0.546)$ than elsewhere along-transect. The most important zooplankton organisms found in the diet were 3 species of euphausiids, crab larvae and copepods (Fig. 10b). The euphausiids Thysanoessa raschii and $T$. inermis were consumed in all 3 regions (Kruskall-Wallis test, $\mathrm{df}=2, \mathrm{n}=44, \mathrm{p}>0.05$ ); $T$. spinifera was found mainly in the stomachs of birds collected at the MFR (Kruskall-Wallis statistic $=9.864$, $\mathrm{n}=2, \mathrm{n}=44, \mathrm{p}=0.007$ ). The proportion of crab larvae (Kruskall-Wallis statistic $=7.484, \mathrm{df}=2, \mathrm{n}=44$, $\mathrm{p}=0.024$ ) and copepods (Kruskall-Wallis statistic $=$ 3.473, $\mathrm{df}=2, \mathrm{n}=44, \mathrm{p}=0.176$ ) was higher offshore of the MFR. Adult stages of T. raschii and T. inermis were consumed in spring; in summer, juvenile euphausiids contributed a large fraction (35\%) to the diet, as did other small zooplankton such as crab larvae and copepods $(39 \%)$. The proportion of zooplankton consumed at the MFR decreased from 99 to $78 \%$ in summer 1997 and 1998, respectively, to $49 \%$ in summer 1999 . The proportion of sandlance in the stomachs of birds collected at the MFR increased in the same period. Sandlance was consumed mainly at and inshore of the MFR (Kruskall-Wallis statistic $=6.22, \mathrm{df}=2, \mathrm{n}=56, \mathrm{p}=0.045$ ). Age-0 gadids, most probably walleye pollock, were consumed predominately offshore of the MFR (Kruskall-Wallis statistic $=12.131, \mathrm{df}=2, \mathrm{n}=56, \mathrm{p}=0.002$ ).

\section{DISCUSSION}

In this study we found large interannual differences in primary production at the inner front related to the anomalous conditions in the Bering Sea during 1997 and 1998 (Hunt et al. 1999a,b, Overland 2001, Stabeno et al. 2001). In 1997, calm weather and a shallow mixed-layer produced conditions that allowed phytoplankton to grow below the thermocline (Stabeno et al. 2001, Kachel et al. 2002). The inner front moved closer to shore than previously recorded (Kachel et al. 2002). Nutrients were depleted early in spring, and few remained into the summer (Stockwell et al. 2001, Kachel et al. 2002). No nutrients were available to be carried to the surface at the inner front; hence primary production did not occur there or was very low (Kachel et al. 2002). In 1998 and 1999, stormy weather and a deeper mixed-layer isolated a reservoir of nutrients in the bottom layer (Stabeno et al. 2001, Kachel et al. 2002). The inner front moved offshore to near the seaward end of the study grids (Kachel et al. 2002). Frequent strong winds throughout spring and summer sustained mixing and delayed the onset of the spring bloom (Kachel et al. 2002). The spring cruises in 1998
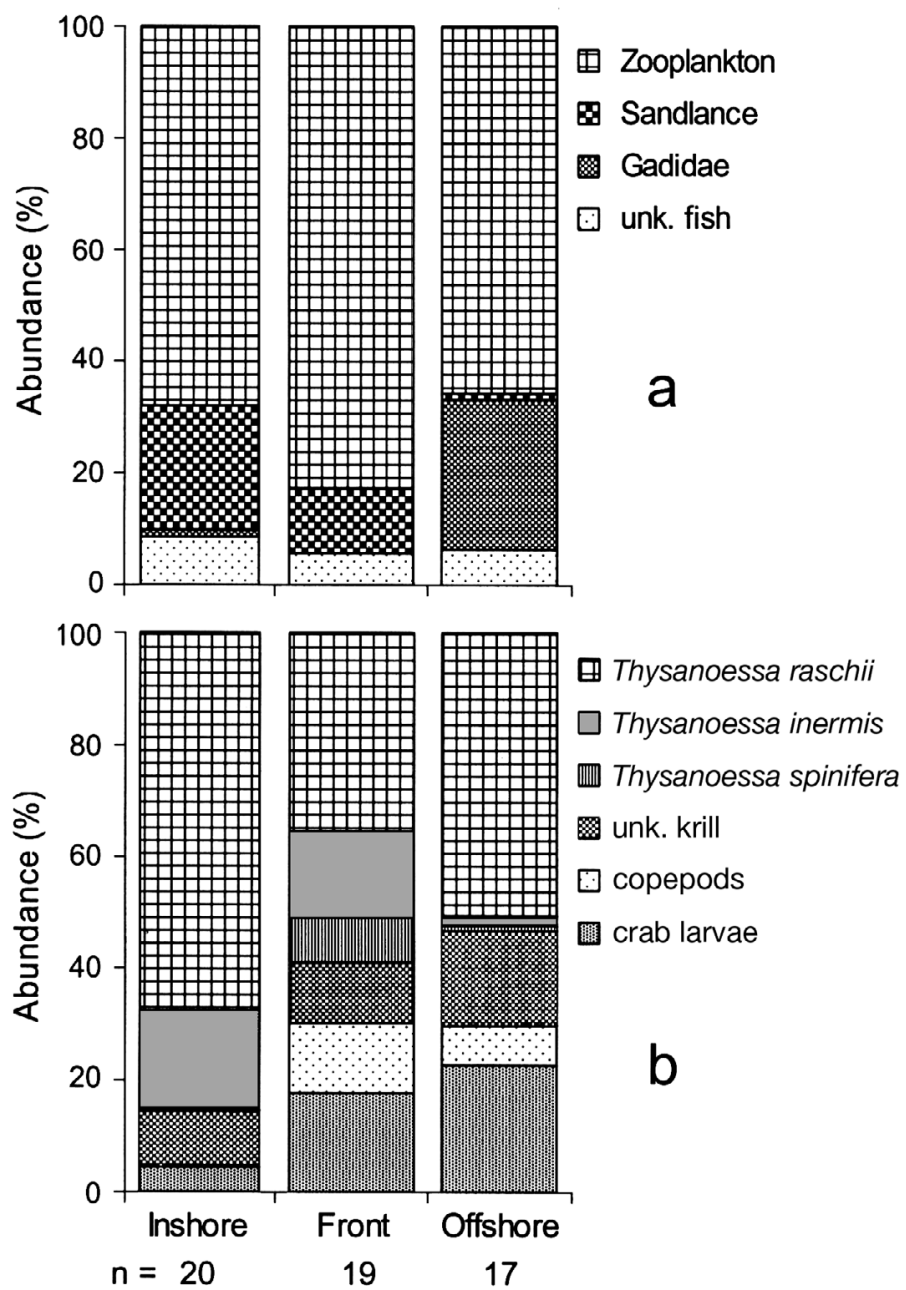

Fig. 10. Puffinus tenuirostris. Diet composition in relation to mean frontal region. (a) Relative consumption of major prey types (by volume); (b) consumption of main zooplankton organisms (by number). n: sample size for each region 
and 1999 took place early in the season, when stratification of the water was just beginning and the bloom was yet to occur (Kachel et al. 2002). Stormy conditions in 1999 delayed the formation of the 2-layered system during spring, and the inner front developed later in the season with colder temperatures and higher nutrient concentrations than the surrounding waters (Kachel et al. 2002).

Primary production during late summer and early fall was higher at the inner front and offshore of the front than inshore of this feature. This was particularly clear in late summer 1999, when abundant cold, nutrient-rich water below the pycnocline led to the conditions required for the inner front to supply nutrients to the upper layers of the water, thus enhancing primary production (Kachel et al. 2002). However, stormy weather played an important role in replenishing nutrients to the upper layer of the well-stratified waters as well; high levels of fluorescence and elevated nutrients were found after storms over the stratified waters and near the inner front in summer 1999 (Kachel et al. 2002, see also Sambroto et al. 1986).

The density of euphausiids in late summer and early fall was higher at the inner front and offshore of the front than inshore of this feature. The presence of Age-0 pollock may have caused an underestimate of euphausiids in these 2 habitats, since their acoustic signal masks the acoustic signal of euphausiids (Coyle \& Pinchuk 2002a). Age-0 pollock were distributed near the thermocline and at the front, and dominated the acoustic record over much of the stratified portion of the study area during late summer and early fall (Coyle \& Pinchuk 2002a). The density of euphausiids was higher at the front in 50 to $80 \%$ of the transects we analyzed using the MFR and PDF, regardless of season. Furthermore, shearwaters foraging at the front were consuming zooplankton and sandlance; Age-0 pollock was consumed predominantly offshore of the frontal region. Shearwaters are opportunistic in their diet and consume the prey most readily available in their foraging range (Ogi et al. 1980). Shearwaters in Bristol Bay have been known to prey almost exclusively on euphausiids (Ogi et al. 1980, Hunt et al. 1981a, 1996, 2002, Schneider et al. 1986). However, their diet changes to mostly fishes in the North Pacific Ocean and mostly squid near the Bering Sea shelfbreak area (Ogi et al. 1980). In the present study, prey consumption by shearwaters suggests high availability of euphausiids and sandlance at the inner front, and Age-0 gadids offshore of this feature. If readily available offshore of the front, euphausiids would probably have been present in larger amounts in the diet, as was observed in 1997.

Euphausiids concentrate at fronts as a consequence of biological (mating or feeding) or physical (conver- gence or divergence) processes. Flow at the inner front has been shown to produce the divergence of the upper layers and convergence of the lower layers of the water column, suggesting a frontal upwelling (Coachman 1986). Frontal upwelling was evidenced by vertical, finger-like structures with elevated nitrate concentration associated with high standing stocks of phytoplankton during summer (Kachel et al. 2002). Areas of enhanced production often attract zooplankton; swarms of Thysanoessa raschii have been observed at the structural front north of St. Paul Island (Pribilof Islands) during July and August (Coyle \& Cooney 1993). Aggregations of euphausiids at the front were probably the result of attraction to ephemeral patches of high primary production. Euphausiids can detect phytoplankton patches (Price 1989), and breeding occurs in the presence of elevated primary production (Paul et al. 1990). Euphausiids form daytime near-surface and surface mating-swarms when spawning during summer (Smith \& Adams 1988, Hanamura et al. 1989), even though most spawning usually occurs during spring (Smith 1991). The presence of juvenile stages of euphausiids in the diet of the birds was probably the result of spring breeding events; juvenile stages were more abundant over the shelf break in the summer than in the spring (Stockwell et al. 2001), as may have occurred in other areas of the Bering Sea shelf.

Some enhancement of zooplankton biomass could occur as consequence of directed swimming behavior, which would physically increase the accumulation of organisms independent of their physiological response to increased production (Franks 1992a). Vertically migrating zooplankton may become concentrated at the surface when swimming against a current (Simard et al. 1986, Coyle et al. 1992). The aggregation of other smaller zooplankton organisms may be due to any physical or/and biological process(es). The aggregation of copepods at a front in the Ligurian Sea was attributed to directive active swimming (Boucher 1984), while aggregations of copepods at fronts in the Irish Sea were associated with high surface chlorophyll a concentrations at the front (Scrope-Howe \& Jones 1985).

Primary production, the aggregation of euphausiids and their later consumption by seabirds and other higher trophic-level predators occur at different spatial and timescales. Nutrient transport at tidal fronts is associated with the periodic effect of tides that break down the stratification of the water, thereby carrying nutrients to the surface (Pingree et al. 1974, 1976, Holligan 1981, Le Fevre 1986). Cyclonic eddies of 20 to $40 \mathrm{~km}$ in diameter that may form along the front and persist for 3 to $4 \mathrm{~d}$ are important in the transfer of heat, salt and nutrients across the stratified regions during summer (Pingree 1978). It takes about $10 \mathrm{~d}$ for nutri- 
ents to build up after the initial formation of the physical feature (i.e. the front) and about 5 more days for phytoplankton to reach maximum levels (Franks 1992b). Nutrients forced into the euphotic zone are incorporated into phytoplankton over a period of days and into zooplankton in a matter of weeks (Franks 1992b). Fronts and other physical features of comparable extent may last for weeks (or months), while seabird aggregations may only last for a few hours (Schneider et al. 1987). The probability of encountering zooplankton aggregations at the front is likely to be much higher than the probability of finding large aggregations of foraging seabirds. Also, while all seabird aggregations at sea are likely to be associated with prey, not all prey aggregations need be exploited by seabirds at a given time (Heinemann et al. 1989).

Shearwaters foraged primarily in shallow inshore waters during late spring and shifted to deeper offshore waters in late summer and early fall. Possible explanations for this shift from coastal to offshore foraging habitats include nutrient depletion in inshore waters and depletion of prey inshore of the front by foraging shearwaters and humpback whales during spring (Hunt et al. 2002). Foraging in the coastal region during spring is advantageous for shearwaters because euphausiid aggregations will be trapped near the bottom and thus easier to locate and exploit in these shallow waters (Genin et al. 1988, Hunt et al. 1996). As nutrients are depleted and production ceases in the coastal domain (Kachel et al. 2002), zooplankton and fishes (i.e. sandlance) will move and aggregate at the front or offshore of this feature, where production continues during summer (Kachel et al. 2002). As the season progresses to summer and fall, the diurnal daylight cycle changes to longer periods of darkness and euphausiids spend more time in the upper layers providing more foraging opportunities for shearwaters over deeper waters (K. O. Coyle unpubl.). The occurrence of these surface patches of euphausiids is somewhat unpredictable, as most aggregations will concentrate near the pycnocline where the chlorophyll maximum is located. Foraging at the front is advantageous during summer because surface aggregations of euphausiids are more easily detected by flying birds. At the front, the pycnocline bends upwards, and patches of phytoplankton that attract euphausiids are closer to the surface than they are farther offshore.

Shearwaters at the inner front foraged on euphausiids and a large fraction of smaller zooplankton. The proportion of zooplankton consumed at the front decreased from summer 1997 to summer 1999, while the consumption of sandlance increased in this area. Calm weather conditions (Stabeno et al. 2001, Kachel et al. 2002) and water turbidity due to the presence of a coccolithophore bloom (Vance et al. 1998, Stockwell et al. 2001) contributed to high mortality of shearwaters in 1997 (Baduini et al. 2001a). Light attenuation resulting from the coccolithophore bloom probably had a negligible influence on underwater foraging; however, greater turbidity and backscatter of light may have impaired the birds' ability to locate prey from the air (Lovvorn et al. 2001), thus increasing their in-flight energy demand (Baduini et al. 2001a). Our results support the idea that birds may not be able to forage successfully inside a coccolitophore bloom even when prey is readily available in the area. In summer 1998, shearwaters were feeding on euphausiids, and more nutrients were available to enhance production at the inner front; however, we did not find more birds and flocks of shearwaters in this area. Stormier conditions (Stabeno et al. 2001, Kachel et al. 2002) probably decreased energy demand for flight in 1998, but the coccolithophore bloom was still there (Napp \& Hunt 2001), reducing their ability to find prey (Baduini et al. 2001a). There was but a minor die-off of shearwaters in 1998 (Hyrenbach et al. 2001), even though their overall body condition was lower than in 1997 (Baduini et al. 2001b). Age-0 pollock were abundant at the outer ends of the transects in 1998 and 1999 late in the season, and shearwaters made use of this prey offshore of the inner front (Baduini et al. 2001b). In summer 1999, the water was colder (Coyle \& Pinchuk 2002b) and there were more nutrients to enhance production at the front (Kachel et al. 2002). More birds and flocks used the inner front this year, consuming euphausiids and sandlance. The overall body condition of the birds in 1999 was better than in 1997 and 1998 (Baduini et al. 2001b) and there was no shearwater die-off (Hyrenbach et al. 2001). However birds were still taking Age-0 pollock as prey.

This paper has shown that there is a clear seasonal change in the foraging habitats of short-tailed shearwaters in the inner domain of the SE Bering Sea, where the inner front is likely to produce an aggregation of zooplankton organisms and higher trophic-level predators during summer and fall. The means by which this aggregation occurs remain obscure, as we found no clear evidence of enhanced production at the front. The inner front has been shown to be an ephemeral feature that forms in spring and recurs 'intermittently' (depending on storm activity) throughout the summer (Kachel et al. 2002). When present, the inner front is likely to prolong primary production into summer, favoring the aggregation of zooplankton and their seabird predators.

Acknowledgements. We thank the captain and crew of the RV 'Alpha Helix' for their support, and all those who helped with data collection during many cruises. J.J. is grateful to N. Karnovsky, C. Maranto, C. Pickens and L. Vlietstra for helping make graduate life at UCI an enjoyable experience. We 
are grateful to A. J. Cullum for writing WinFlock. We thank A. D. Long and M. M. Riehle for modifying the RiehleTRON. C. Rintoul provided a base map of the Bering Sea area. F. L. Carpenter, D. M. Checkley Jr, B. A. Hawkins and N. Karnovsky provided useful comments that improved the quality of this manuscript. J.J. was supported by a Graduate Assistance in Areas of National Need (GAANN) Fellowship while writing up this paper. This research was supported in part by National Science Foundation Office of Polar Programs grant NSF-OPP-9617287 and 9819251 to G.L.H. Jr. and NSF-OPP9907097 to S.I.Z. This publication was funded by the Joint Institute for the Study of the Atmosphere and Ocean (JISAO) under NOAA Cooperative Agreement No. NA17RJ1232, Contribution No. 1078. This research was sponsored by NOAA's Coastal Ocean Program through Southeast Bering Sea Carrying Capacity, and is contribution FOCI-S515 to Fisheries-Oceanography Coordinated Investigations. It is Pacific Marine Environmental Laboratory Contribution No. 2714.

\section{LITERATURE CITED}

Baduini CL, Hyrenbach KD, Coyle KO, Pinchuk A, Mendenhall V, Hunt GL Jr (2001a) Mass mortality of short-tailed shearwaters in the south-eastern Bering Sea during summer 1997. Fish Oceanogr 10:117-130

Baduini CL, Lovvorn JR, Hunt GL Jr (2001b) Determining the body condition of short-tailed shearwaters: implications for migratory flight ranges and starvation events. Mar Ecol Prog Ser 222:265-277

Begg GS, Reid JB (1997) Spatial variation in seabird density at a shallow sea tidal mixing front in the Irish Sea. ICES J Mar Sci 54:552-565

Boucher J (1984) Localization of zooplankton populations in the Ligurian marine front: role of ontogenic migration. Deep-Sea Res 31:469-484

Caldeira RMA, Russell P, Amorim A (2001) Evidence of an unproductive coastal front in Baia d'Abra, an embayment on the south east of Madeira Island, Portugal. Bull Mar Sci 69:1057-1072

Coachman LK (1986) Circulation, water masses, and fluxes on the southeastern Bering Sea shelf. Contin Shelf Res 5: 23-108

Coyle KO, Cooney RT (1993) Water column sound scattering and hydrography around the Pribilof Islands, Bering Sea. Contin Shelf Res 13:803-827

Coyle KO, Pinchuk AI (2002a) The abundance and distribution of euphausiids and zero-age pollock on the inner shelf of the southeast Bering Sea near the inner front in 1997-1999. Deep-Sea Res 49:6009-6030

Coyle KO, Pinchuk AI (2002b) Climate-related differences in zooplankton density and growth on the inner shelf of the southeastern Bering Sea. Prog Oceanogr 55:177-194

Coyle KO, Hunt GL Jr, Decker MB, Weingartner TJ (1992) Murre foraging, epibenthic sound scattering and tidal advection over a shoal near St. George Island, Bering Sea. Mar Ecol Prog Ser 83:1-14

Durazo R, Harrison NM, Hill AE (1998) Seabird observations at a tidal mixing front in the Irish Sea. Estuar Coast Shelf Sci 47:153-164

Fogg GE (1984) Biological activities at a front in the western Irish Sea. In: Gibbs PE (ed) Proceedings of the Nineteenth European Marine Biology Symposium. Cambridge University Press, Cambridge, p 87-95

Fogg GE, Egan B, Floodgate GD, Jones DA and 5 others (1985) Biological studies in the vicinity of a shallow-sea tidal mixing front. VII. The frontal ecosystems. Philos Trans R Soc Lond B 310:555-571

Franks PJS (1992a) Sink or swim: accumulation of biomass at fronts. Mar Ecol Prog Ser 82:1-12

Franks PJS (1992b) Phytoplankton blooms at fronts patterns scales and physical forcing mechanisms. Rev Aquat Sci 6: 121-137

Genin A, Haury L, Greenblatt P (1988) Interaction of migrating zooplankton with shallow topography: predation by rockfishes and intensification of patchiness. Deep-Sea Res 35:151-175

Hanamura Y, Kotori M, Hamaoka S (1989) Daytime surface swarms of the euphausiid Thysanoessa inermis off the west coast of Hokkaido, northern Japan. Mar Biol 102: 369-376

Haney JC, Solow AR (1992) Testing for resource use and selection by marine birds. J Field Ornithol 63:43-52

Heinemann D, Hunt G, Everson I (1989) Relationships between the distributions of marine avian predators and their prey Euphausia superba in Bransfield Strait and Southern Drake Passage, Antarctica. Mar Ecol Prog Ser 58:3-16

Holligan PM (1981) Biological implications of fronts in the northwest Eurpoean continental shelf. Philos Trans R Soc Lond A 302:547-562

Hunt GL Jr, Burgeson B, Sanger GA (1981a) Feeding ecology of seabirds of the Eastern Bering Sea. In: Hood DW, Calder JA (eds) The Eastern Bering Sea Shelf: oceanography and resources, Vol 2. University of Washington Press, Seattle, p 629-647

Hunt GL Jr, Gould PJ, Forsell DJ, Peterson H (1981b) Pelagic distribution of marine birds in the Eastern Bering Sea. In: Hood DW, Calder JA (eds) The Eastern Bering Sea Shelf: oceanography and resources, Vol 2. University of Washington Press, Seattle, p 689-718

Hunt GL Jr, Coyle KO, Hoffman S, Decker MB, Flint EN (1996) Foraging ecology of short-tailed shearwaters near the Pribilof Islands, Bering Sea. Mar Ecol Prog Ser 141: $1-11$

Hunt GL Jr, Baduini CL, Brodeur RD, Coyle KD and 6 others (1999a) Ecosystem responses of the southeastern Bering Sea to abnormal weather patterns in 1997 and 1998. Int Counc Explor Sea Comm Meet 1999/O 06

Hunt GL Jr, Baduini CL, Coyle KO, Kachel NB and 7 others (1999b) The Bering Sea in 1998: the second consecutive year of extreme weather-forced anomalies. EOS Transactions, Am Geophy Un 80:565-566

Hunt GL Jr, Mehlum F, Russell RW, Irons DB, Decker MB, Becker PH (1999c) Physical processes, prey abundance, and the foraging ecology of seabirds. In: Adams N, Slotow R (eds) Proceedings of 22nd International Ornithology Congress. Birdlife South Africa, Johannesburg, p 2040-2056

Hunt GL Jr, Baduini C, Jahncke J (2002) Diets of short-tailed shearwaters in the southeastern Bering Sea. Deep-Sea Res 49:6147-6156

Hyrenbach KD, Baduini CL, Hunt GL Jr (2001) Line transect estimates of short-tailed shearwater Puffinus tenuirostris mortality in the south-eastern Bering Sea, 1997-1999. Mar Ornithol 29:11-18

Iverson RL, Curl HC Jr, O'Connonrs HB Jr, Kirk D, Zakar K (1974) Summer phytoplankton blooms in Auke Bay, Alaska driven by wind mixing of the water column. Limnol Oceanogr 19:271-278

Iverson RL, Coachman LK, Cooney RT, English TS and 6 others (1979a) Ecological significance of fronts in the southeastern Bering Sea. In: Livingston RJ (ed) Ecological processes in coastal and marine systems. Plenum Press, New York, p 437-465 
Iverson RL, Whitledge TE, Goering JJ (1979b) Chlorophyll and nitrate fine structure in the southeastern Bering Sea shelf break front. Nature 281:664-666

Kachel NB, Hunt GL Jr, Salo SA, Schumacher JD, Stabeno PJ, Whitledge TE (2002) Characteristics and variability of the inner front of the southeastern Bering Sea. Deep-Sea Res 49:5889-5909

Le Fevre J (1986) Aspects of the biology of frontal systems. Adv Mar Biol 23:163-299

Lovvorn JR, Baduini CL, Hunt GL (2001) Modeling underwater visual and filter-feeding by planktivorous shearwaters in unusual sea conditions. Ecology 82:2342-2356

Maguer JF, L'Helguen S, Le Corre P (2000) Nitrogen uptake by phytoplankton in a shallow water tidal front. Estuar Coast Shelf Sci 51:349-357

Mann KH, Lazier JRN (1996) Dynamics of marine ecosystems: biological-physical interactions in the ocean, 2nd edn. Blackwell Scientific Publications, Cambridge

Marshall AJ, Serventy DL (1956) The breeding cycle of the short-tailed shearwater, Puffinus tenuirostris (Temminck), in relation to trans-equatorial migration and its environment. Proc Zool Soc Lond 127:489-510

Napp JM, Hunt GL Jr (2001) Anomalous conditions in the south-eastern Bering Sea 1997: linkages among climate, weather, ocean, and biology. Fish Oceanogr 10:61-68

Neu CW, Byers CR, Peek JM (1974) A technique for analysis of utilization-availability data. J Wildl Manag 38:541-545

Ogi H, Kubodera T, Nakamura K (1980) The pelagic feeding ecology of the Short-tailed Shearwater Puffinus tenuirostris in the Subarctic Pacific Region. J Yamashina Inst Ornithol 12:157-182

Overland JE, Bond NA, Adams JM (2001) North Pacific atmospheric and SST anomalies in 1997: links to ENSO? Fish Oceanogr 10:69-80

Parsons TR, Maita Y, Lalli CM (1984) A manual of chemical and biological methods for seawater analysis. Pergamon Press, New York

Paul AJ, Coyle KO, Ziemann DA (1990) Timing of spawning of Thysanoessa raschii (Euphausiacea) and occurrence of their feeding-stage larvae in an Alaskan Bay. J Crustac Biol 10:69-78

Pingree RD (1978) Cyclonic eddies and cross-frontal mixing. J Mar Biol Assoc UK 58:955-963

Pingree RD, Forster GR, Morrison GK (1974) Turbulent convergent tidal fronts. J Mar Biol Assoc UK 54:469-479

Pingree RD, Pugh PR, Holligan PM, Forster GR (1975) Summer phytoplankton blooms and red tides along tidal fronts in the approaches to the English Channel. Nature 258: 672-677

Pingree RD, Holligan PM, Mardell GT, Head RN (1976) The influence of physical stability on spring, summer and autumn phytoplankton blooms in the Celtic Sea. J Mar Biol Assoc UK 56:845-873

Price HJ (1989) Swimming behavior of krill in response to algal patches: a mesocosm study. Limnol Oceanogr 34: 649-659

Riehle MM, Bennett AF, Long AD (2001) Genetic architecture of thermal adaptation in Escherichia coli. Proc Natl Acad Sci USA 98:525-530.

Sambroto RN, Niebauer HJ, Goering JJ, Iverson RL (1986) Relationships among vertical mixing, nitrate uptake and phytoplankton growth during the spring bloom in the southeast Bering Sea middle shelf. Contin Shelf Res 5: 161-198

Schneider D (1982) Fronts and seabird aggregations in the southeastern Bering Sea. Mar Ecol Prog Ser 10:101-103 Schneider DC, Shuntov VP (1993) The trophic organization of the marine bird community in the Bering Sea. Rev Fish Sci 1:311-335

Schneider DC, Hunt GL Jr., Harrison NM (1986) Mass and energy transfer to seabirds in the southeastern Bering Sea. Contin Shelf Res 5:241-257

Schneider D, Harrison NM, Hunt GL Jr (1987) Variation in the occurrence of marine birds at fronts in the Bering Sea. Estuar Coast Shelf Sci 25:135-141

Schumacher JD, Kinder TH, Pashinski DJ, Charnell RL (1979) A structural front over the continental shelf of the Eastern Bering Sea. J Phys Oceanogr 9:79-87

Scrope-Howe S, Jones DA (1985) Biological studies in the vicinity of a shallow-sea tidal mixing front. Part V. Composition, abundance and distribution of zooplankton in the western Irish Sea, April 1980 to November 1981. Philos Trans R Soc Lond B 310:501-519

Shuntov VP (1993) Biological and physical determinants of marine bird distribution in the Bering Sea. In: Vermeer $\mathrm{K}$, Briggs KT, Morgan KH, Siegel-Causey D (eds) The status, ecology, and conservation of marine birds of the North Pacific. Canadian Wildlife Service, Ottawa, p 20-26

Simard Y, Ladurantaye R, Therriault JC (1986) Aggregation of euphausiids along a coastal shelf upwelling environment. Mar Ecol Prog Ser 32:203-215

Smith SE, Adams PB (1988) Daytime surface swarms of Thysanoessa spinifera (Euphausiacea) in the Gulf of the Farallones, California. Bull Mar Sci 42:76-84

Smith SL (1991) Growth development and distribution of the euphausiids Thysanoessa raschi (M. Sars) and Thysanoessa inermis (Krøyer) in the Southeastern Bering Sea. Polar Res 10:461-478

Stabeno PJ, Bond NA, Kachel NB, Salo SA, Schumacher JD (2001) On the temporal variability of the physical environment over the south-eastern Bering Sea. Fish Oceanogr 10:81-98

Stockwell DA, Whitledge TE, Zeeman SI, Coyle KO, Napp JM, Brodeur RD, Pinchuk AI, Hunt GL Jr (2001) Anomalous conditions in the south-eastern Bering Sea, 1997: nutrients, phytoplankton and zooplankton. Fish Oceanogr 10:99-116

Tasker ML, Jones PH, Dixon T, Blake BF (1984) Counting seabirds at sea from ships: a review of methods employed and a suggestion for a standardized approach. Auk 101: 567-577

Vance TC, Baier CT, Brodeur RD, Coyle KO and 10 others (1998) Aquamarine waters recorded for first time in eastern Bering Sea. EOS Trans Am Geophys Un 79:121-126

Vidal J, Smith SL (1986) Biomass, growth, and development of populations of herbivorous zooplankton in the southeastern Bering Sea during spring. Deep-Sea Res 33:523-556

Walsh JJ, McRoy CP (1986) Ecosystem analysis in the southeastern Bering Sea. Contin Shelf Res 5:259-288

Warham J (1990) The petrels, their ecology and breeding systems. Academic Press, London

Zeeman SI (1992) The importance of primary production and $\mathrm{CO}_{2}$. In: Nagel PA (ed) Results of the third joint US-USSR Bering and Chukchi Seas expedition, summer 1989. US Fish \& Wildlife Service, Washington, DC, p 218-224

Zeeman SI, Jensen PR (1990a) Modeling primary production in the Bering Sea. US Fish Wildl Serv Biol Rep 90:74-86

Zeeman SI, Jensen PR (1990b) Photoresponses of phytoplankton in the Bering Sea. US Fish Wildl Serv Biol Rep 90: $87-96$

Submitted: July 27, 2004; Accepted: May 26, 2005

Proofs received from author(s): December 5, 2005 